Please cite this paper as: Wan, K., Haklay M., and Lorke J (2020) Exploring factors associated with participation in citizen science among UK museum visitors aged 40-60: A qualitative study using the theoretical domains framework and the capability opportunity motivation-behaviour model. Public Understanding of Science. DOI:

$10.1177 / 0963662520963511$.

\title{
Exploring factors associated with participation in citizen science among UK museum visitors aged 40-60: A qualitative study using the theoretical domains framework and the capability opportunity motivation-behaviour model.
}

\section{Abstract}

Citizen science has grown as a form of public engagement in science. Middle-aged citizens who are already consuming scientific information should be a potential outreach group. Behaviour change research in citizen science participation amongst the demographic is lacking. 47 museum visitors age 40-60 took part in qualitative structured and semi-structured interviews. Thematic analysis with the aid of theoretical domains framework and capability opportunity motivation-behaviour model revealed eight themes: (1) limited awareness of citizen science; (2) curiosity, competence, and other significant characteristics and skills; (3) important beliefs about one's capability; (4) importance of clear project purpose and impacts; (5) interest, enjoyment, and incentives; (6) lasting impacts of family upbringing; (7) project details that make participation easy, better project promotion, (8) the living environment, availability of free time and money. Addressing a maximum number of these factors with behaviour change techniques can improve the likelihood of citizen science participation.

\section{Background}

Citizen science is a form of research that engages the public to participate voluntarily through co-designing research goals, data collection, analysis, interpretation or dissemination of information (Haklay, 2013; Miller-Rushing et al., 2012). It allows professional researchers to generate new knowledge based on vast amounts of data from across locations and time periods otherwise not feasible (Dickinson et al., 2012; McKinley et al., 2017). For the public, citizen science provides opportunities for situated learning (Lave and Wenger, 1991), build community stewardship and sense of belonging, foster social wellbeing and interest for natural science (Bonney et al., 2016; Haywood et al., 2016; Varner, 2014).

The act of joining and participating in a citizen science project for the first time can be considered as a behavioural change. We can therefore consider the process of identifying effective strategies to achieve this behaviour as critical to the success of a citizen science project. Existing studies revealed that citizen science participation is biased towards the middle-aged and those with stability in life (West, Dyke, et al., 2016; West and Pateman, 2016). For older adults, social activities and engagement in volunteer activities are associated with better health and wellbeing (Croezen et al., 2009; Huxhold et al., 2014). Since this age group seems more willing to participate and would benefit from a maintained behaviour change, it is worth considering how we can encourage this to happen. 
A potential way to consider participation in citizen science is to see it as part of a continuum of public engagement in science. The DITOs' escalator model (DITOs Consortium, 2016) describes public participation in science as engagement levels (see Figure 1). It starts with the consumption of scientific information in a passive way and show progression through deeper modes of engagement, culminating in forms of Do-It-Yourself Science meaning participants shape the research questions and instruments. This model does not exclude the possibility of someone participating at several levels over the same period of time. According to this model, active consumption of science information, e.g. by visiting a science museum, is the level immediately below limited contributory participation such as joining a citizen science project (Shirk et al., 2012). As behaviour change is more likely to occur when perceived as achievable in small, easy steps (Hill, 2009; Service et al., 2014), it should be easier to recruit active consumers of science into citizen science than people who are only passively engaging. Combining this with the age demographic consideration above, it follows that middle-aged individuals actively consuming science information is a highly appropriate target audience for citizen science recruitment efforts.

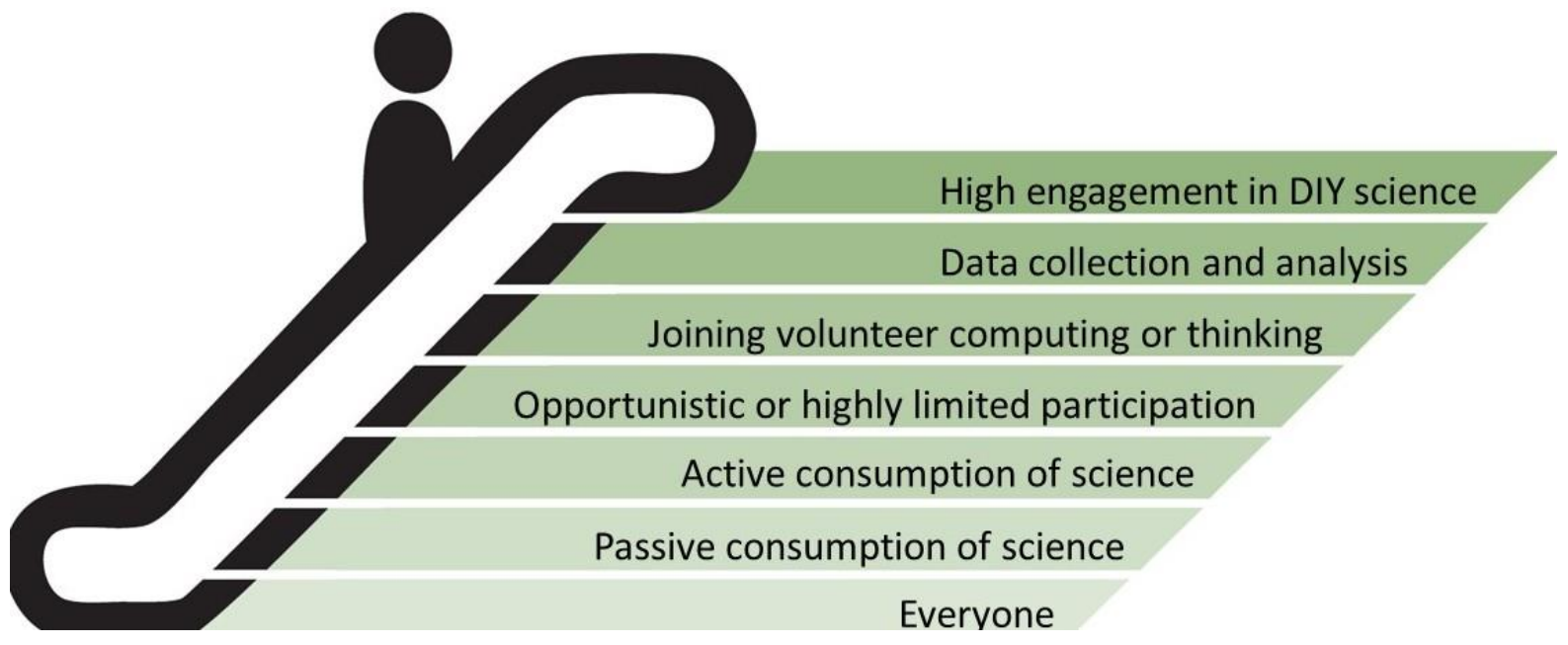

Figure 1. The Escalator Model in the DITOs project

Existing literature often emphasise the recruitment and participation of young people or a broad age range (Ballard et al., 2017; Herodotou et al., 2020; Lee et al., 2018; West and Pateman, 2016). Work or family engagements, limited access to projects, and socio-economic deprivation have been suggested as participation barriers (Southby and South, 2016). More focused analyses of the participation influencing factors for the middle-aged remain limited (West, Dyke, et al., 2016; West and Pateman, 2016).

Fewer than half of all registered citizen science participants actually submitted any data (West, Pateman, et al., 2016), revealing an intention-behaviour gap (Moghavvemi et al., 2015). Behaviour change science addresses this by analysing determinants of the target behaviour of "taking part in citizen science" with a theoretical framework and proposing techniques for achieving the action.

One such framework is the "capability opportunity motivation-behaviour" (COM-B) model (Michie et al., 2014). It posits that a behaviour only occurs if the person has the capability to enact, motivation to engage, and opportunities to do so, and that these factors are constantly 
changing. By using COM-B and the escalator model to study a target change in engagement levels, the dynamic and non-linear nature of the process is addressed. Mapping out the facilitating and hindering factors for a target behaviour using COM-B is the basis of an evidence-based intervention design tool called the behaviour change wheel, which is used to select the most suitable techniques for achieving the targeted change (Michie et al., 2011). Here, too, the view is not one that assumes people to be acting as automatons with their buttons pushed and changed, but as social actors which can have different roles and actions, and the tools of behaviour change science are there to provide the ability to offer opportunities in an appropriate way.

An evidence-based tool that aids COM-B application in qualitative data analysis is the Theoretical Domains Framework (TDF) (Atkins et al., 2017). TDF consists of 14 domains that provide more nuances to the COM-B constructs, facilitating the understanding of the target behaviour. The correlations between TDF domains and COM-B constructs are illustrated in Table 1.

Table 1. Mapping TDF domains to COM-B constructs.

\begin{tabular}{|c|c|c|}
\hline TDF Domain & COM-B Constructs & \\
\hline Skills & Physical capability & \multirow{5}{*}{ Capability } \\
\hline Knowledge & \multirow{4}{*}{$\begin{array}{l}\text { Psychological } \\
\text { capability }\end{array}$} & \\
\hline Skills & & \\
\hline $\begin{array}{l}\text { Memory, attention and decision } \\
\text { Processes }\end{array}$ & & \\
\hline Behavioural regulation & & \\
\hline $\begin{array}{l}\text { Social/professional role and } \\
\text { identity }\end{array}$ & \multirow{6}{*}{ Reflective motivation } & \multirow{8}{*}{ Motivation } \\
\hline Beliefs about capabilities & & \\
\hline Optimism & & \\
\hline Beliefs about consequences & & \\
\hline Intentions & & \\
\hline Goals & & \\
\hline Reinforcement & \multirow[t]{2}{*}{ Automatic motivation } & \\
\hline Emotion & & \\
\hline $\begin{array}{l}\text { Environmental context and } \\
\text { resources }\end{array}$ & Physical opportunity & \multirow[t]{2}{*}{ Opportunity } \\
\hline Social influences & Social opportunity & \\
\hline
\end{tabular}




\section{Aims and methodological approach}

The overarching aim of this study was to explore factors associated with participation in natural science-related citizen science projects, using the TDF and COM-B as analysis frameworks. This study focuses on middle-aged natural science museum visitors, as they fall within the target audience hypothesised to have a higher likelihood for change in respect to the target behaviour of participating in citizen science.

Ensuring a shared understanding of citizen science with study participants was crucial because it would affect the definition of the target behaviour. Little was known about how laypersons conceptualise citizen science and levels of participation, despite increasing attention within the academic community (Lewandowski et al., 2017). Thus, our first research question was: what were the understandings of citizen science and active participation in science amongst middle-aged museum visitors?

The second research question was: what and how factors influence participation in citizen science?

To address these questions, we designed a qualitative study with two phases of data collection. The first was a structured interview using fourteen questions to get an overview of the informants' knowledge about citizen science, the facilitating and hindering factors for participation. The second phase started after themes had emerged from phase one data and used a semi-structured interview to further explore these themes.

The Natural History Museum (NHM) and the Grant Museum of Zoology in London were chosen as recruitment sites. The NHM was chosen because it is a major natural science establishment with a high visitor numbers. It also runs regular citizen science projects, which could help put the study in context for the potential participants. The Grant Museum of Zoology was chosen because it is in the same category of natural science establishments as the NHM and is part of University College London where the first and second author were based. Having two recruitment sites allowed better purposive recruitment for participants and obtaining a larger data set.

To allow purposive recruitment and check for informant diversity, the following demographic information were collected: how often the participant visited museums/ science exhibitions; how they rated their interest in natural science and in citizen science participation; participant's gender, age, occupation, education background, and (interview participants only) income level and cultural identity.

There is fluidity in the definition of "middle age". The Oxford English Dictionary (2002) posits the age range of 45-60; the European Social Survey suggested people perceived youth to end at age 40 and old age to start at 62 (Abrams et al., 2011). This study defined the target population as persons aged 40-60. Other inclusion criteria were UK residence, fluent English speaking, and voluntary consent to take part. Recruitment took place between $28^{\text {th }}$ March and $13^{\text {th }}$ June 2019. Recruited individuals participated in either one of the phases, not both.

\section{Data collection and data analysis}

Phase one interviews (hereafter referred to as "scoping") were administered on site. Phase two interviews (hereafter "interview") were conducted by phone. Answers were read/listened 
through once every three completed data records for purposive sampling, to identify emerging themes, check for data saturation, and review the need for question modifications.

For interviews, general questions on capability, motivation and opportunities were used, as well as more specific follow-up questions based on TDF using formulations by Huijg et al. (2014) as reference. The final version of the questions used for the two phases are provided as supplemental material 1 and 2 .

The interviews were audio-recorded, transcribed verbatim with the aid of an online automated transcription service Trint, and proof-read to ensure accuracy.

Transcripts were analysed thematically using the framework approach combined with a deductive approach at the start (Gale et al., 2013; Pope et al., 2000), then iterating between inductive and deductive coding. The qualitative analysis tool NVivo v.12 was used. TDF was used as the coding framework to allow for a more fine-grained analysis of influencing factors. A table illustrating the coding process is attached as supplemental material 3 . The resulting themes were mapped over to COM-B to facilitate interpretation of the findings and identification of interventions to improve citizen science participation.

\section{Findings}

A total of 226 persons were approached and 32 took part in the scoping. For the interview, 93 persons were approached and 15 participated. Reasons for rejection included: person did not meet inclusion criteria, participation would take too much time, lack of interest, not wanting to take part etc. The recruitment periods and outcomes for both phases are shown in supplemental material 4.

The sex ratio of the participants was even. The age spreads were similar in the scoping and interview group. A smaller proportion of scoping participants had heard of or taken part in citizen science compared to the interview group. On a self-rating scale of 1-10, the average interest for natural science and citizen science was higher than 5 in both groups. The majority of participants had higher education. Most of the interviewees identified themselves as British. The majority of interviewees had an income level above the national median (Webber and O'Neill, 2019). The details are shown in supplemental material 5.

For phase one, data saturation was reached after 29 participants. Three extra entries were completed for certainty. For phase two, data saturation was not reached but recruitment was terminated as the planned recruitment period ended. All themes found during scoping were also present in the interview data, but some details differed. More personal characteristics were described by scoping participants, likely due to question formulations. Data from interviews were more nuanced, and more motivation factors were described.

We identified eight themes influencing citizen science participation, situated within and across TDF and COM-B domains. These were: (1) the understanding of citizen science and conceptualisation of active versus passive participation in science; (2) personal characteristics and skills of significance; (3) beliefs about one's own capability to take part; (4) consequences perceived as important; (5) interest, enjoyment, and incentives; (6) impacts of family; (7) project details and project promotions; (8) a person's time, living location, and 
money. The details are presented below, with the relevant COM-B construct specified in each theme heading, and TDF domains indicated in italics and in brackets.

\section{The understanding of citizen science and active participation in science: Psychological Capability}

The participants understood citizen science in a range of ways (knowledge). Of the total 47 participants, 36 considered it as some form of active engagement in science; 34 suggested that citizen science was laypersons contributing to research, and that there would be a largescale project supported by scientists, making a big impact by recruiting many individuals.

I suppose, you know, to me it sounds like, it sounds like encouraging, encouraging people from the general public to become involved in science and help with, um and help with research. So it tells me something that's, that's led by, led by an organisation and is sort of enlisting the help of people. (Interview: male, age 51)

Bigger number makes bigger impact. (Scoping: male, age 56)

Seven participants expected citizen science to improve laypersons' understanding of science by making science more accessible or passing on knowledge. Two persons answered that it would involve physical work.

In the scoping group, five thought that citizen science related to environmental activities such as recycling, or activities related to the local community. This perception was not as prevalent in the interview group. In the interview group, two participants thought the term described how one interacts with the world in a responsible way, and four were not sure what the term could mean as they considered it vague.

Participants also had varied conceptualisations of active and passive participation in science (knowledge). There was no cut-off activity that marked the difference between the two levels of engagement. For active participation, 34 participants defined it as actually doing something, contributing, or partaking with a purpose by active choice.

... I mean you are actually making a conscious decision to do something.... You make a sort of conscious decision to go on to do something positive for science. (Interview:

female, age 55)

Seven participants said active participation meant they had taken part in the activity themselves. Six conceptualised it as activities that required physical work.

Passive participation was conceptualised as just observing, taking in work done by others, and something that was happening in the background.

\section{Personal characteristics and skills of significance: Psychological and Physical Capability}

Having curiosity (memory, attention and decision process) was the personal characteristic most often mentioned as important for participation. Another trait considered to be important was having patience. Aspects of competence were described as facilitating, such as a good 
understanding for what the citizen science project was asking for, being thorough and accurate, and timely data submission (cognitive skills).

What do you think are the 3 most important attributes that a person must have to contribute in a natural science project in this way?

.... Patience. Science is not quick. (Scoping: male, age 55)

Competent in what they are doing, the task they are asked to do. (Scoping: male, age 52) Basic physical wellbeing (physical skills) was considered influential, though five informants pointed out its significance depends on the project tasks required. Computer skills (cognitive skills) were mentioned as necessary by four participants, for recognising security risks and submitting data. Three interviewees mentioned that shyness would make participation in group activities less likely, and confidence in interactions with others would make it easier (interpersonal skills).

\section{Beliefs about one's own capability to take part: Reflective Motivation}

24 participants shared the belief that no specific knowledge or skill was required to take part in citizen science (beliefs about capabilities). Exact requests might depend on the individual project, but there would be a level for everyone.

... because the spectrum is wide. So at one end you might need none, just be a breathing [person] and have some way of actually taking information in, either by your ears or your eyes, your tongue, and your senses. And at the other end you might probably need a bit more, and supremely more. But no, we all have the capacity. (Interview: female, age 41)

However, ten participants thought a certain level of knowledge in the research topic would be necessary, so the person could understand what he/she should be looking for.

Yes. They would be able to take part. But I think they wouldn't get the full enjoyment out of it.... If you don't have background information you wouldn't see the bigger picture. I think that's always a waste if you don't get that information. It's like if you go out and look at birds and don't know what birds they are... (Interview: female, age 44)

Five interview participants answered that some specific knowledge might be needed but that could be acquired once the person had joined the project, through teaching from the project staff or self-learning. Hence it should not limit the capacity for one to take part.

About half of the informants said they knew how to find information about current/future citizen science projects. Almost everyone in the other half believed it would be easy to do so. The main channels mentioned were online, and through science organisations. Other ways cited were through newspaper, television, word of mouth, and local councils. No participant mentioned unfamiliarity with smart devices as a hinderance.

\section{Consequences perceived as important: Reflective Motivation}

If the informants perceived a project to be lacking a clear purpose, not handling data properly, or not using the right methods for its aims (beliefs about consequences), they would 
not want to participate. Local topics, environmental focuses, or wildlife protection might encourage participation.

The potential impact of the project (beliefs about consequences) both at local and national/international level was considered salient by 17 informants. This is because they wanted to help and make a difference for issues, they considered imperative (goals). They wanted to understand who could benefit from the project and aspired to contribute to the wider science community.

...not just like results in your own local area but to know what kind of impact that's having in a big, wider. You know it's sort of like a national- in a local or a national level.... Reward people with the fact that this tiny bit that you've done got this massive impact for us here [emphasis added]. I think, I think that for people of my age I would think that's quite an important thing. (Interview: female, age 51)

Four informants thought individuals who wanted to learn new things (goals) would be more likely to take part in citizen science. Gaining knowledge and broadening one's horizon were mentioned by 12 of the 15 interviewees as benefits of participation (beliefs about consequences). Taking part in citizen science could raise awareness for the environment and wildlife, provide knowledge as a basis for solving problems, give new life perspectives, and keep oneself mentally and physically fit.

\section{Interest, enjoyment, and incentives: Automatic Motivation}

12 interviewees and 22 scoping participants considered interest (emotion) to be key for involvement in citizen science. Interest could also motivate a person to search for information and learn about a citizen science topic.

I think it's one of those things. you're only happy to do it if it's of a particular subject interest to yourself. (Interview: female, age 51)

Nine interviewees said enjoyment (emotion) would be a reason for them to take part.

Well, if people take part it's because they want to enjoy it ... I mean I'd never do something if that's just not enjoyable or of some interest so. (Interview: male, age 58)

Four participants considered material or virtual rewards as an incentive. By contrast, 13 asserted that feedback and feeling good were important (reinforcement). Timely feedback about the results of the study to the project could help participants see the impact of their contribution. Personalised feedback and follow-up contact after the event were appreciated. Two interviewees said it would be demoralising if no feedback was given.

And then we take the coordinates from us, so. And then immediately on the map it would appear, the new spatter. And the roadkill adds on. And you gain that as well, the reward, the new spatters on the map, so yeah. (Interview: female, age 41)

Taking part in citizen science was described by three interviewees as empowering, bringing a sense of achievement. Those who had participated before enjoyed the experience and felt good about helping research. 


\section{Impacts of family: Social Opportunity and Reflective Motivation}

Persons identifying themselves as someone who enjoyed the outdoors, interested in nature and cared about the environment (identity) were considered more likely to take part in citizen science. Nature-interested parents, science profession in the family, an upbringing in the countryside or one that encourage outdoor activities (social influences in the past) were noted by 13 participants as factors that forged who they became. Senior family members' role as a guide for the young to develop and maintain interest was highlighted.

I grew up in a household where my parents planted plants for insects, and they were keen on birds. I grew up identifying birds and plants, watching nature documentaries. My parents were members of WWF, Wildlife Trust. So, I've always had an interest as a child and now a life-long interest. (Scoping: female, age 56)

For these participants, getting actively involved in citizen science projects was not seen as something that required change, rather as a family tradition.

It wasn't that I decided to do that, no. It's just, it's just there in my genes I suppose. Just

your parents did it, your grandparents did it. you do it. (Interview: female, age 57) Having children in the household could influence participation in either way (social influence). Six informants would take part in a project to interact with their children/ grandchildren. One person said specifically that they would not initiate participation themselves but would be happy to join if the children wanted to and needed help. If the children were not interested in science, participation would be more difficult.

Overall, interviewees expected support from their close ones (social influences) but did not think it a determinant for participation.

\section{Project details and project promotions: Physical Opportunity}

Knowing the details of the citizen science project was important in deciding whether to take part. Participants wanted to know who was organising the project, what tasks were involved, and where the project was carried out (environmental context and resources). Two interviewees mentioned that they would prefer universities or museums because companies might be biased. 12 said they would be more likely to take part if instructions were clear, and tasks and data submission were easy such as through interactive mobile applications.

It's just a difference if they've got a decent programme, for you can then send things off.... If you are asked to submit things then you want it to be fairly easy to be able to do it. (Interview: female, age 55)

Local or easily accessible project locations were preferred. Three reflected that long travels would be associated with costs and time.

If there's anything local that would be great. Possibly if It's something I can do in the comfort of my own home. (Interview: male, age 55)

As a barrier for particiption, 11 interviewees mentioned that they were not aware of current projects (knowledge). Many informants, particularly those who had taken part in citizen science before, observed that it was not often they came across information on available 
projects through various media channels (environmental context and resources). Some felt that people probably would not search actively.

There are few people that actively think "I'm going to join a, a citizen science project", so, you know. But they might, if they go in somewhere and they go into a museum and they see a leaflet or an advert for it they might. But I don't think people would actively, certainly people of my generation I'm thinking of people I work with and stuff, they wouldn't actively look for it. (Interview; female, age 51)

14 participants felt that effective promotion of projects (environmental context and resources) was needed for better information access and recruitment. A website where one could search for all current/future projects by topic or location was desirable. Messages should be simple and easy to grasp. Social media were considered good communication tools, while persistent emailing was considered off-putting. Well-known spokesperson or representatives of the project could be an advantage. Using narratives to sell a story could add persuasive power.

\section{A person's time, location, and money: Physical Opportunity}

Time was a determining factor for 34 of the 47 participants (Environmental context and resources). They were more willing to take part if the project tasks could fit into their already busy schedule. Nine informants mentioned that they had not participated in citizen science despite interest because work limited their free time, and they had other things to prioritise. Likelihood of participation was larger if the project did not require long-term commitments. There was no difference between the number of participants who preferred to be able to plan ahead for better time management, preferred spontaneous participation, or had no preference.

According to the informants, participation in citizen science tended not to be a result of any special events. However, 14 participants did associate it with a change in the stage of life (Environmental context and resources), for example having children, working, or entering retirement. Having children and working full-time would mean having less free time. Participants expected themselves to be more likely to take part when they became older or retired, as they would then have more free time.

31 participants thought location would influence their citizen science participation. Apart from the importance of project location described above, a person's place of residence was named by eight persons as also relevant (Environmental context and resources). Easy access to museums, hobby clubs or nature areas would facilitate interest in science and active participation.

I was interested in the sciences and the rockets, and you know, building your own rockets... I was looking into that, again in the UK it's not so prevalent as it's in the US. That type of club it is something I'd, if there is more chance to get involved in activities doing that, I would consider that. (Interview: male, age 58)

Having ample monetary resources was described as a facilitating factor for citizen science participation. One interviewee described how having money to travel to exotic locations stimulated his appreciation for nature and made him determined to help in any way he could. 
Another explained that well-off parents could have leisure to mentor their child, and better afford to take part in projects.

I think there may be children who are interested but I think they still need hand holding or leading through. And maybe the parents haven't got the time or the energy. If you're a person who's working very long hours just to put food on the table... Maybe they'd love to do it but they just don't have the time and energy to do that. (Interview: female, age 57)

\section{Discussion}

\section{Strengths and limitations}

A strength of the study was the use of two data collection methods for triangulation. Findings from interviews validated and complimented those from scoping. Even though the interview data were not saturated, clear themes emerged. The last few interviews were only expanding the range of contents in existing themes.

A difficulty during data analysis and construction of the logic model was the uncertainty about under which TDF domain certain contents should be coded. Often these had arisen from insufficient follow-up questions during data collection. For example, when an informant had said they would be more likely to participate in citizen science if the topic was local, during coding it became unclear whether this was an environmental context or beliefs about consequences (that such projects would have local impact). To mitigate this issue, the first author obtained help from three MSc in Behaviour Change students at UCL both during deductive and inductive coding to reach the final logic model. As the finalised themes and matched TDF domains were not checked by any informant, the constructed understanding was bound by the researchers' perspective as citizen science developers and behaviour change students. An improvement by future studies is to apply a participatory design to better explore the informants' views.

There was a participation bias that was clearer in the interview group than the scoping group. While it is estimated that only a small percentage of the population is actively engaged in citizen science projects (Haklay, 2016; Nielsen, 2006), far more than 10\% of all participants had taken part in citizen science, in the interview group it was over $50 \%$. On average the interviewees were more interested in taking part in citizen science than scoping participants.

\section{Capability influencing Motivation}

In several ways, the findings supported the COM-B prediction that capability affects motivation.

Citizen science was not a well-recognised term amongst participants. Though they could often guess a meaning that matches the academic concept, the term was not something they had noticed prior to this study. 15 participants had taken part in citizen science activities, yet answered "no" when asked if they had heard of the term before or taken part in other sciencerelated activities than museum visits. This finding echoed with findings from a previous study on how "citizen science" was defined differently by different stakeholders and rarely used in communication with participants (Geoghegan et al., 2016). Many participants were familiar 
with names of individual projects rather than the concept of citizen science. This can be a barrier for the interchange of knowledge between the public and scientists, hindering the popularisation of citizen science participation.

Informants did not identify any point of change from passive to active participation. Many participated concurrently in activities they defined as active and those seen as passive. The informants' conceptualisations of active participation in science did not match their understandings of citizen science. If these had been matching, it might form an additive effect feeding into the motivation to take part in citizen science, as making a contribution or impact were strong motivating factors. The lack of awareness and understanding for the phrase citizen science, and heterogenous conceptualisation of active participation in science could thus influence citizen science participation negatively.

Almeida et al. (2008) showed that persons with stronger curiosity and exploratory tendencies were more willing to volunteer. Our results support curiosity as a key characteristic for participation and that it was closely linked to the automatic motivation of having an interest in science topics. Also, being curious or patient contributes to a person's attention and decision process, improving their self-efficacy in tasks and motivation for participation.

\section{Motivation}

In line with previous studies that investigated motivation for participation in citizen science (Geoghegan et al., 2016; Slattery et al., 2019), our data on beliefs about consequences and goals reflected egoism, altruism, and collectivism. Egoism was indicated by the described goal of personal learning, the perceived importance of getting personalised feedback, the mentioned participation benefits of obtaining enjoyment and empowerment. Altruism was apparent in that many informants said contributing to science would strongly encourage them to take part. Collectivism could be seen from the significance of local/national impacts, and that informants found local projects to be more relevant for them.

\section{Opportunities influencing Motivation}

Füchslin et al. (2019) suggested that inadequate public outreach would lead to significant impairment of citizen science potentials. Our participants commented on the lack of welldeveloped websites in the UK for finding available citizen science projects. According to COM-B, this limitation in physical opportunities should impact motivation for participation in citizen science. Interestingly, in terms of beliefs about capabilities, almost all informants seemed unaffected by this existing opportunity limitation and either said they knew how to find information about citizen science projects or believed it would be easy to do so.

Some of the findings did support the COM-B prediction of opportunities influencing motivation, namely the impacts of family, and a person's time and money.

The impact of family upbringing seemed pivotal from the data of this study. Apart from material resources, the family passed on practices and preferences resulting from education and cultural capital (Eriksen, 2015) to the child, who could develop a lasting interest in science as part of their identity. The child would be more likely to participate in citizen science later in life. Indeed, previous research suggested cultural capital as a key determinant 
for volunteering behaviour of the elderly (Youssim et al., 2015). So, social influences during childhood shape a person's identity and behaviour throughout their lifetime, i.e. opportunities can affect motivation and behaviour not just in the moment, but over time. Intergeneration transmission of both material and cultural capital implies participation inequality could be associated with social class and persist over generations.

Families are also part of a person's social capital: social networks and relations that construct norms and provide interpersonal support for behaviours (Israel et al., 2001; Legh-Jones and Moore, 2012). Existing literature informs that social capital ownership predicts higher level of volunteering (Glanville et al., 2016; Southby and South, 2016). Though approval from close ones was not considered deterministic by the interviewees, they all expected a supportive norm. Social norms influence behaviour according to many established behaviour theories (Michie et al., 2014). Thus, the findings suggested that both cultural and social capital facilitate citizen science participation.

The effects of opportunities on motivation was also demonstrated by the emphasis informants placed on time and life stages. Haklay (2016) posited that voluntary project participation was a function of leisure time. Amount of leisure time varies with stages of life, but changes in life stage could also lead to changes in motivation. Having young children at home and being retired were the two phases of life mentioned as participation transforming. These time periods are associated with shifts of social roles; new goals emerge such as interacting with young family members or preventing negative effects of aging. Therefore, a person's motivation for citizen science participation should change over time under the effects of varied opportunities.

\section{Implications of findings}

This is an exploratory qualitative study on factors influencing the change from nonparticipation to participation in citizen science amongst middle-aged persons in the UK, thus findings cannot be generalised. However, they can be constructed into a preliminary logic model (supplemental material 6) based on COM-B as a step in finding effective citizen science recruitment strategies.

Using the logic model and the behaviour change wheel, relevant intervention functions were identified and potential behaviour change techniques (BCTs) with intervention contents for increasing participation proposed (examples shown in Table 2, and the full proposal is attached as supplemental material 7). Due to the sparsity of behaviour change research related to citizen science, only some of the possible intervention contents were informed by literature. For BCTs with no relevant literature found, intervention suggestions were based on the study data and definitions of BCTs. 
Table 2. Example of proposed interventions for increasing citizen science participation.

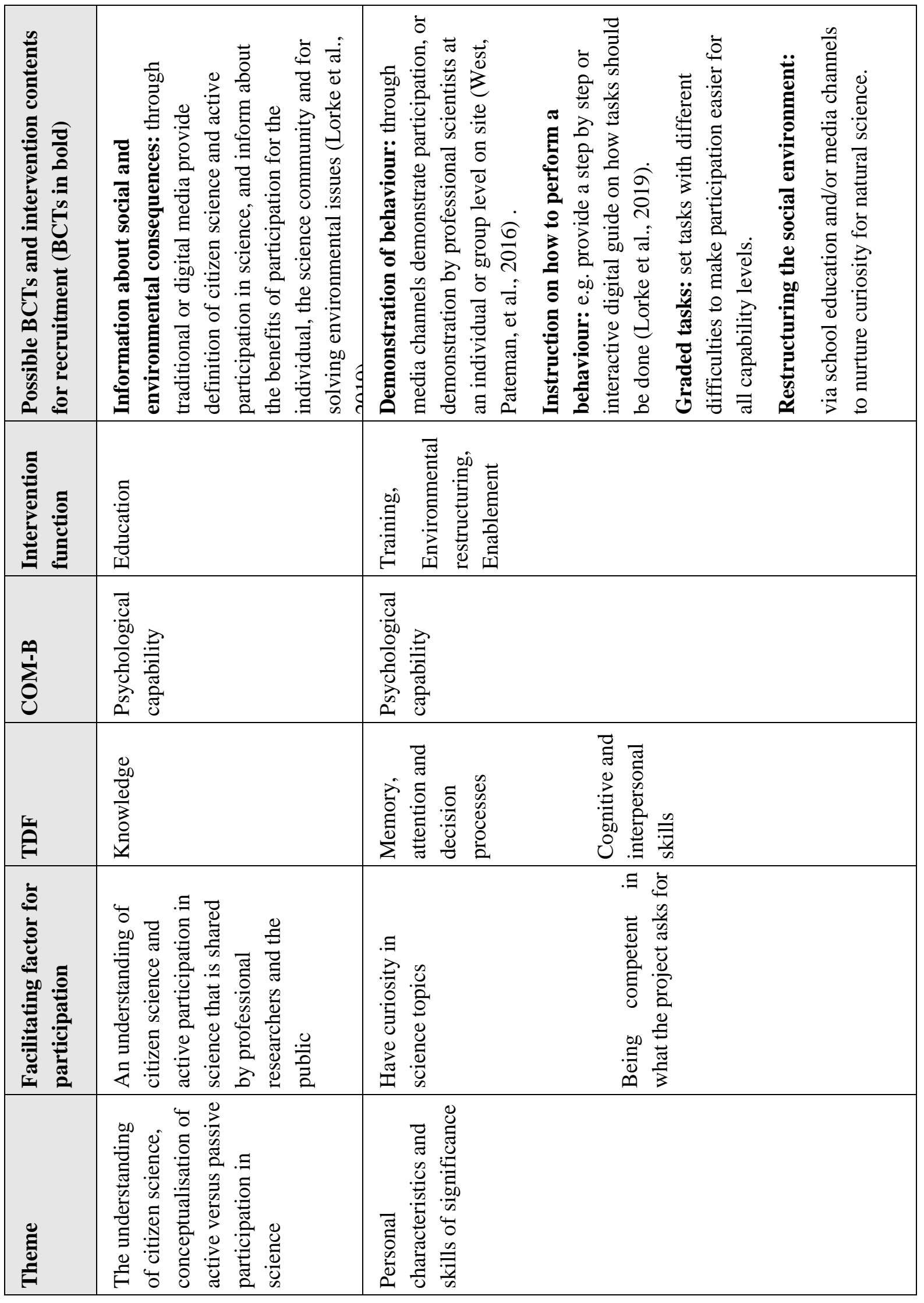


To improve the public's understanding of and active participation in citizen science, organisations can advertise a standardised and simple definition of the term with information on the benefits of participation. To foster curiosity and competence, organisations can demonstrate performance of the tasks required (West et al., 2016), provide a step-by-step interactive guide, or collaborate with schools to nurture curiosity in the young. To strengthen the public's beliefs about their own capability to take part, project organisers can highlight project success in previous years and the range of contribution levels laypersons can take, demonstrate the behaviour, and suggest ways to overcome barriers in recruitment materials. Organisations can emphasise the benefits of participation for both the participant and on a broader community or population levels (Lee et al., 2018; Varner, 2014). To address interest, enjoyment and incentives, organisers can highlight the fun elements of tasks (Dickinson et al., 2012), provide interactive feedback (Varner, 2014), and maintain follow-up contacts after a completed project (Crall et al., 2017). To enhance the family-ingrained identity as a science participant, projects can encourage the public to record their own science contributions, and show the proportion of the middle-aged population already participating in citizen science. Social opportunities can be increased for the coming generations of this target demographic by engaging adults to encourage their children to take part, and increasing curriculum-based citizen science projects (Bonney et al., 2016). Marketing strategies can be employed to better promote projects (Crall et al., 2017; Varner, 2014). Creating a database where the public can search for current/future projects by topic, location, time etc will improve public outreach. Project organisers should provide clear information about the tasks involved, time required (West and Pateman, 2016), and the range of locations participants can choose from. Information about the flexibilities in time commitments and what can be done without monetary costs can encourage people to take part.

Further research from a behaviour change perspective using qualitative and quantitative methods can add nuances and themes onto this preliminary logic model to improve it. Each citizen science project organiser should choose specific BCTs based on their project context and budget, after evaluating the feasibility and suitability of each BCT based on its affordability, practicability, effectiveness/cost-effectiveness, acceptability, potential sideeffects, and equity issues. To maximise the likelihood of people in the target population taking part in citizen science, as many facilitating factors as possible under each of the COMB constructs should be provided.

\section{Conclusion}

Amongst UK residents age 40 - 60 who participated in this study, awareness of the term citizen science was limited. Participants' conceptualisations of active participation in science were heterogenous and did not match that of citizen science.

Personal characteristics, the purpose and impacts of the project, learning and other benefits for themselves all influenced informants' likelihood of joining in citizen science. Pre-existing levels of knowledge and skills were not seen as a requirement. Family upbringing affected the cultural and social capital of the individual, their identity and motivation to take part. Project details that make participation easy, better project promotions could further facilitate the behaviour change. A person's time, place of living, and money were significant physical 
constraints for motivation and enactment of participation. The findings supported the correlations between COM-B constructs.

This study offers a comprehensive behaviour change framework to explore public participation in citizen science. For middle-aged UK residents already consuming science information at museums, their capability, motivation and opportunity all need to be addressed to maximise their likelihood of taking part in a natural science-oriented citizen science project. Further behaviour change research with qualitative and quantitative methods will build on findings of this study, and help designing the most appropriate intervention strategies for increasing public participation in citizen science.

\section{Ethics Approval}

Ethical approval was granted by the UCL Research Ethics Committee, project ID: 14511/001.

\section{Acknowledgement}

The authors would like to thank the NHM and the Grant Museum for allowing the data collection to happen in their setting; and Anna Clifford, Leo de Winter, and Nadine FontainPalmer of cohort 2018-19 in MSc in Behaviour Change at UCL for their contribution in the data analysis process.

\section{Funding}

This research received no specific grant from any funding agency in the public, commercial, or not-for-profit sectors.

\section{Conflict of Interest}

The authors declare that there is no conflict of interest. 


\section{References}

Abrams D, Russell PS, Vauclair C-M, et al. (2011) Ageism in Europe - Findings from the European Social Survey. Available at: www.eurage.com (accessed 9 July 2019).

Almeida L, Kashdan TB, Coelho R, et al. (2008) Healthy subjects volunteering for Phase I studies: Influence of curiosity, exploratory tendencies and perceived self-efficacy. International Journal of Clinical Pharmacology and Therapeutics 46(3): 109-118. DOI: 10.5414/cpp46109.

Atkins L, Francis J, Islam R, et al. (2017) A guide to using the Theoretical Domains Framework of behaviour change to investigate implementation problems. Implementation Science 12(1). Implementation Science: 1-18. DOI: 10.1186/s13012017-0605-9.

Ballard HL, Dixon CGH and Harris EM (2017) Youth-focused citizen science: Examining the role of environmental science learning and agency for conservation. Biological Conservation 208. The Authors: 65-75. DOI: 10.1016/j.biocon.2016.05.024.

Bonney R, Phillips TB, Ballard HL, et al. (2016) Can citizen science enhance public understanding of science? Public Understanding of Science 25(1): 2-16. DOI: 10.1177/0963662515607406.

Crall A, Kosmala M, Cheng R, et al. (2017) Volunteer recruitment and retention in online citizen science projects using marketing strategies: lessons from Season Spotter. Journal of science communication 16(01): A01. DOI: 10.22323/2.16010201.

Croezen S, Haveman-Nies A, Alvarado VJ, et al. (2009) Characterization of different groups of elderly according to social engagement activity patterns. The Journal of Nutrition, Health and Aging 13(9): 776-781. DOI: 10.1007/s12603-009-0213-8.

Dickinson JL, Shirk J, Bonter D, et al. (2012) The current state of citizen science as a tool for ecological research and public engagement. Frontiers in Ecology and the Environment 10(6): 291-297. DOI: 10.1890/110236.

DITOs Consortium (2016) Doing It Together science: D3.1 DITOs WEB. London. Available at: http://togetherscience.eu/content/3-about/2-deliverables/5-doing-it-together-scienced3-1-ditos-web/ditos-d3.1-20170130.pdf (accessed 18 August 2019).

Eriksen TH (2015) Small Places, Large Issues : An Introduction to Social and Cultural Anthropology. 4th ed. London: Pluto Press.

Füchslin T, Schäfer MS and Metag J (2019) Who wants to be a citizen scientist? Identifying the potential of citizen science and target segments in Switzerland. Public understanding of Science: 1-17. DOI: 10.1177/0963662519852020.

Gale NK, Heath G, Cameron E, et al. (2013) Using the framework method for the analysis of qualitative data in multi-disciplinary health research. BMC Medical Research Methodology 13: 117. DOI: 10.1186/1471-2288-13-117.

Geoghegan H, Dyke A, Pateman R, et al. (2016) Understanding Motivations for Citizen Science Final report on behalf of the UK Environmental Observation Framework by. Available at: www.ukeof.org.uk (accessed 31 July 2019).

Glanville JL, Paxton P and Wang Y (2016) Social Capital and Generosity: A Multilevel Analysis. 45(3): 526-547. DOI: 10.1177/0899764015591366.

Haklay M (2013) Citizen Science and Volunteered Geographic Information: Overview and Typology of Participation. In: Sui D, Elwood S, and Goodchild M (eds) Crowdsourcing 
Geographic Knowledge Volunteered Geographic Information (VGI) in Theory and Practice. Dordrecht: Springer Netherlands.

Haklay M (2016) Why is participation inequality important? In: Capineri C, Haklay M, Huang H, et al. (eds) European Handbook of Crowdsourced Geographic Information., pp. 35-44. DOI: 10.5334/bax.c.

Haywood BK, Parrish JK and Dolliver J (2016) Place-based and data-rich citizen science as a precursor for conservation action. Conservation Biology 30(3): 476-486. DOI: 10.1111/cobi.12702.

Herodotou C, Aristeidou M, Miller G, et al. (2020) What Do We Know about Young Volunteers? An Exploratory Study of Participation in Zooniverse. Citizen Science: Theory and Practice 5(1): 1-14. DOI: 10.5334/cstp.248.

Hill JO (2009) Can a small-changes approach help address the obesity epidemic? A report of the Joint Task Force of the American Society for Nutrition, Institute of Food Technologists, and International Food Information Council. The American journal of clinical nutrition 89(2): 477-484. DOI: 10.3945/ajcn.2008.26566.

Huijg JM, Gebhardt WA, Crone MR, et al. (2014) Discriminant content validity of a theoretical domains framework questionnaire for use in implementation research. Implementation Science 9(11). DOI: 10.1186/1748-5908-9-11.

Huxhold O, Miche M and Schüz B (2014) Benefits of having friends in older ages: Differential effects of informal social activities on well-being in middle-aged and older adults. Journals of Gerontology - Series B Psychological Sciences and Social Sciences 69(3): 366-375. DOI: 10.1093/geronb/gbt029.

Israel GD, Beaulieu LJ and Hartless G (2001) The Influence of Family and Community Social Capital on Educational Achievement*. Rural Sociology 66(1): 43-68. DOI: 10.1111/j.1549-0831.2001.tb00054.x.

Lave J and Wenger E (1991) Situated Learning. Legitimate Peripheral Participation. Cambrdige: Cambridge University Press.

Lee TK, Crowston K, Harandi M, et al. (2018) Appealing to different motivations in a message to recruit citizen scientists: results of a field experiment. Journal of Science Communication 17(1): A02. DOI: 10.22323/2.17010202.

Legh-Jones H and Moore S (2012) Network social capital, social participation, and physical inactivity in an urban adult population. DOI: 10.1016/j.socscimed.2012.01.005.

Lewandowski E, Caldwell W, Elmquist D, et al. (2017) Public Perceptions of Citizen Science. Citizen Science: Theory and Practice 2(1). Ubiquity Press. DOI: 10.5334/cstp.77.

Lorke J, Golumbic YN, Ramjan C, et al. (2019) Training needs and recommendations for Citizen Science participants, facilitators and designers. COST Action 15212 report. UK, 15 Nov.

McKinley DC, Miller-Rushing AJ, Ballard HL, et al. (2017) Citizen science can improve conservation science, natural resource management, and environmental protection. Biological Conservation 208. Elsevier Ltd: 15-28. DOI: 10.1016/j.biocon.2016.05.015.

Michie S, van Stralen MM and West R (2011) The behaviour change wheel: a new method for characterising and designing behaviour change interventions. Implementation science : IS 6. BioMed Central: 42. DOI: 10.1186/1748-5908-6-42. 
Michie S, West R, Campbell R, et al. (2014) ABC of Behaviour Change Theories. First Edit. Silverback Publishing.

Miller-Rushing A, Primack R and Bonney R (2012) The history of public participation in ecological research. Frontiers in Ecology and the Environment 10(6): 285-290. DOI: $10.1890 / 110278$.

Moghavvemi S, Akma N, Salleh M, et al. (2015) Effect of external factors on intentionbehaviour gap. Behaviour \& Information Technology 34(12): 1171-1185. DOI: 10.1080/0144929X.2015.1055801.

Nielsen J (2006) The 90-9-1 Rule for Participation Inequality in Social Media and Online Communities. Available at: https:/www.nngroup.com/articles/participation-inequality/ (accessed 3 August 2019).

Oxford English Dictionary (2002) middle age. Oxford English Dictionary. Third Edit. Available at:

https://www.oed.com/view/Entry/118142?redirectedFrom=middle+age\#eid (accessed 9 July 2019).

Pope C, Ziebland S and Mays N (2000) Qualitative research in health care Analysing qualitative data. British Medical Journal 320(7227): 114-116. Available at: https://www.jstor.org/stable/25186804 (accessed 24 July 2019).

Service O, Hallsworth M, Halpern D, et al. (2014) EAST Four simple ways to apply behavioural insights. Available at: https://www.behaviouralinsights.co.uk/wpcontent/uploads/2015/07/BIT-Publication-EAST_FA_WEB.pdf (accessed 25 July 2019).

Shirk JL, Ballard HL, Wilderman CC, et al. (2012) Public participation in scientific research: A framework for deliberate design. Ecology and Society 17(2). DOI: 10.5751/ES-04705170229.

Slattery P, Finnegan P and Vidgen R (2019) Creating compassion: How volunteering websites encourage prosocial behaviour. Information and Organization 29(1): 57-76. DOI: 10.1016/j.infoandorg.2019.02.001.

Southby K and South J (2016) Volunteering, inequalities and barriers to volunteering: $a$ rapid evidence review. Available at: http://eprints.leedsbeckett.ac.uk/3434/1/Barriers to volunteering - final 21st November 2016.pdf.

Varner J (2014) Scientific outreach: Toward effective public engagement with biological science. BioScience 64(4): 333-340. DOI: 10.1093/biosci/biu021.

Webber D and O'Neill J (2019) Average household income, UK: Financial year ending 2018. Available at:

https://www.ons.gov.uk/peoplepopulationandcommunity/personalandhouseholdfinances /incomeandwealth/bulletins/householddisposableincomeandinequality/yearending2018\# analysis-of-average-income (accessed 4 August 2019).

West S and Pateman R (2016) Recruiting and Retaining Participants in Citizen Science: What Can Be Learned from the Volunteering Literature? Citizen Science: Theory and Practice 1(2): 1-10. DOI: $10.5334 /$ cstp.8.

West S, Pateman R and Dyke A (2016) Data Submission in Citizen Science Projects Report for Defra (Project number PH0475). Available at: https://www.york.ac.uk/media/sei/documents/publications/projectreports/West-Pateman- 
Dyke-DEFRA-Data-Submission-in-Citizen-Science-Projects.pdf (accessed 17 August 2019).

West S, Dyke A and Pateman R (2016) Why do people take part in citizen science? Available at: https://www.sei.org/featured/why-do-people-take-part-in-citizen-science/ (accessed 7 December 2018).

Youssim I, Hank K and Litwin H (2015) The role of family social background and inheritance in later life volunteering: Evidence from SHARE-Israel. 37(1): 3-17. DOI: $10.1177 / 0164027513519450$. 